\title{
An Account of Recent Data on Smoking-Related Buerger's Disease and Progression to Necrosis
}

\author{
M Ishaq Khan*, Junaid Khan, Sheikh I Ahmed and Sajjad A \\ Prime Institute of Epidemiology, Public Health, Pakistan
}

Submission: April 20, 2018; Published: July 03, 2018

*Corresponding author: M Ishaq Khan, Prime Institute of Epidemiology, Public Health, Peshawar Pakistan, Tel: +92-321-9730408;

Email: ishaqkhan1@gmail.com

Abstract

Objective: The objective of this review article is to briefly synthesize the most current information and data regarding smoking-induced Buerger's disease, its occasional progression to gangrene, and its treatment and prognosis (Figure 1).

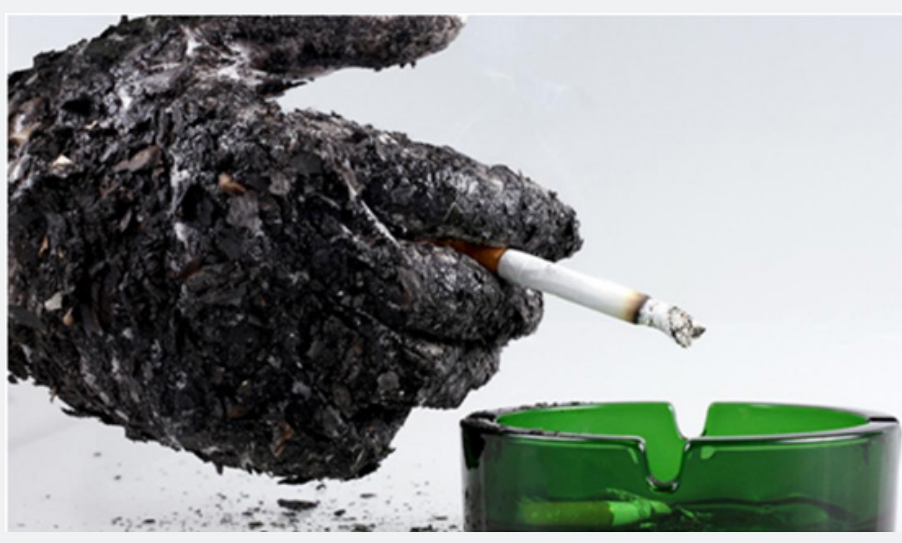

Figure 1

Methodology: A literature search was conducted using Pub Med and Medscape databases for article published between 2013 and 2016 using keywords relevant to the objective of the review. After eliminating irrelevant results, the authors read each article in its entirety to determine applicability for inclusion. A more general web search for synthesis articles and government documents was also conducted.

Results: Buerger's disease is much more common among males than females and exhibits a dose-response relationship with frequency and duration of smoking. Early diagnosis, successful smoking cessation, and proper nursing care are associated with good prognosis. In cases where patients develop gangrenous necrosis associated with Buerger's disease, prognosis is poorer. However amputation is not inevitable. Amputation is associated with complex infection and evidence of occlusion in the main arteries.

Conclusion: It is concluded that continued emphasis on smoking prevention and cessation is important, particularly in developing countries, where a lack of data may allow tobacco companies to claim that their products are not harmful. Buerger's disease, Thromboangiitis obliterans, tobacco use.

Keywords: Smoking; Peripheral vascular disease; Gangrene

\section{Review Summary}

In this review, the authors describe the most recent data related to Buerger's disease (thromboangiitis obliterans) and associated gangrenous necrosis. In the introduction, the authors briefly describe Buerger's disease and associated tissue death.
A methodology section describes the method of conducting the review, including the keywords and databases used. The results are organized into sections covering the signs and symptoms, etiology and epidemiology, progression and diagnosis, and treatment. A discussion concludes the review (Figure 2). 


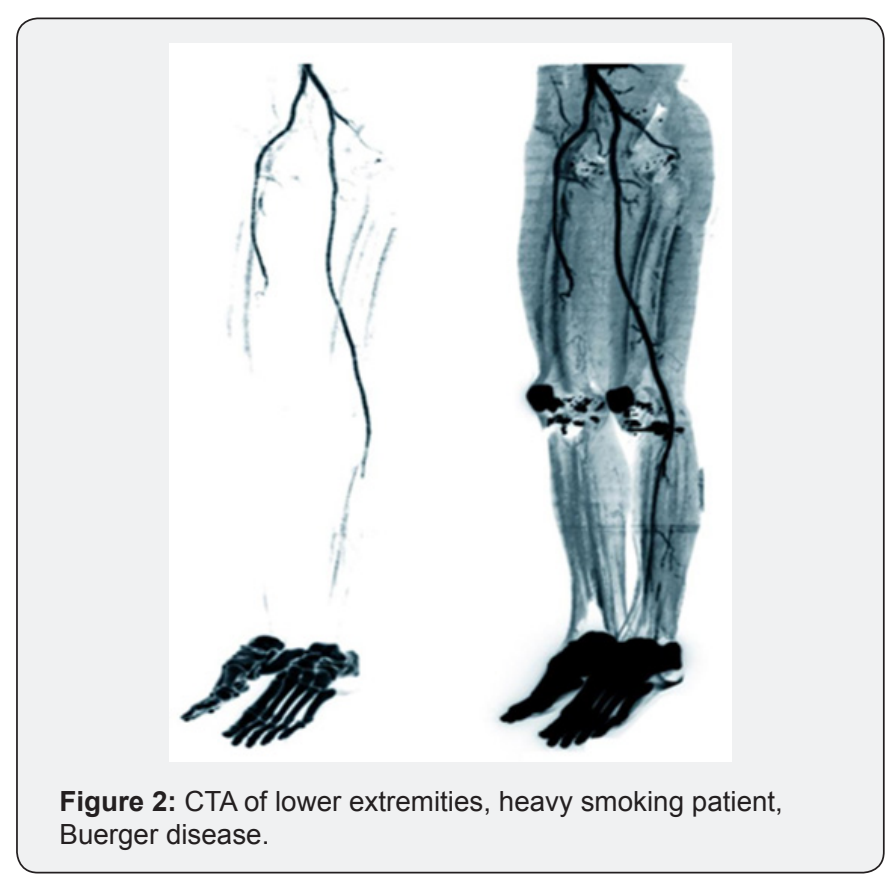

\section{Introduction}

Long history of smoking has been associated with intermittent inflammatory occlusion of the arteries and veins of the extremities. Such occlusion can result in variable circulatory impairment of fingers and toes. In severe cases, this leads to thromboangiitis obliterans (Buerger's disease), a rare disease that primarily affects young and middle-aged male cigarette smokers (Figure 3). The objective of this review is to synthesize recent data related to the prevalence, prognosis, and treatment of Buerger's disease and associated tissue death in the terminal phases of the disease.

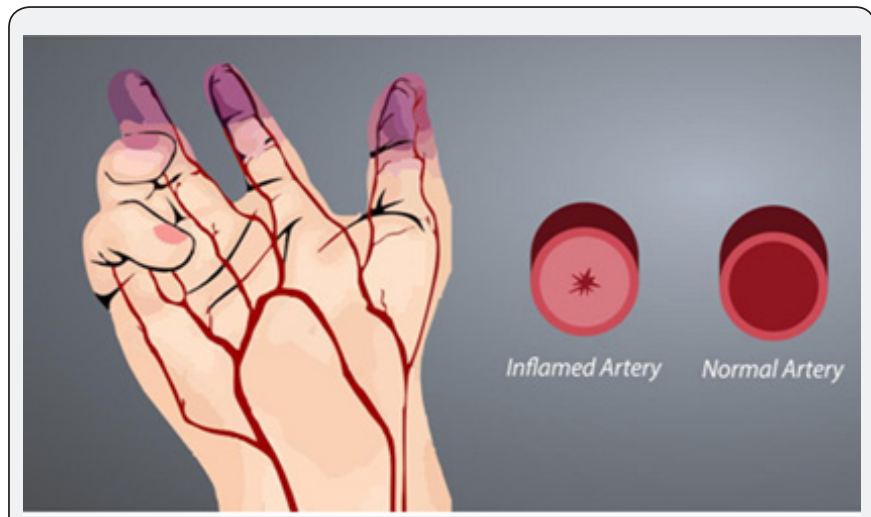

Figure 3: Smoking followed by dangerous health consequences (Burger's Disease).

\section{Methodology}

This review was conducted using searches of scholarly literature published between 2013 and 2016. To locate relevant articles, the authors searched the Pub Med and Medscape databases using the following search terms, alone and in combination: smoking, tobacco use, Buerger's disease, thrombiangiitis obliterans, tissue death, gangrene. Next, the researchers reviewed the abstracts of all search results to determine their relevance to the objective of this review. Articles dealing with circulatory impairment of the extremities associated with history of tobacco use were considered for inclusion (Figure 4). To extract data, the authors read each selected article in its entirety and recorded the sample, setting, method, result, and conclusion of each. Finally, a wider internet search was conducted using Google to identify relevant government documentation pertaining to treatment guidelines. The articles selected for inclusion are reviewed in the results section.

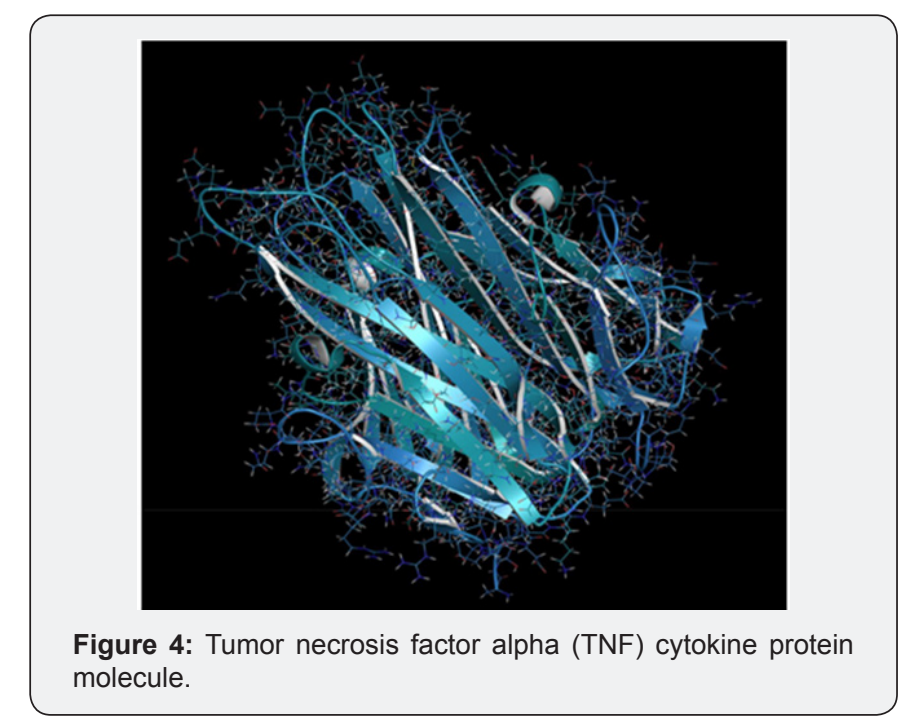

\section{Results}

\section{Signs and symptoms}

Buerger's disease is designated by tapering or obstruction (occlusion) of both the veins and arteries of the extremities, resulting in reduced blood flow to these parts (peripheral vascular disease). It may occur with or without clotting of veins (thrombophlebitis). Early symptoms of peripheral vascular disease include intermittent burning or pricking pain of legs or arms; diminished sensation; painful movements of limbs; fever; impaired pulsation ofulnar, and radial posteriortibialdorsalispedis; paleness in affected extremities; coldness to touch; perception of heat to touch, owing to acute inflammatory changes and in some, painful indolent ulceration along the nail margins [1]. In the majority of cases, the initial presenting symptom is severe pain of the lower arms and legs in resting position. The diseases victims may also experience spasm in the legs when are walking that, in some cases, may cause limp (claudication). On elevation, there may be no changes in skin coloration of pale extremities, which may be markedly engorged when inflamed. Additionally, affected individuals may have sores (open lesions) on one or both extremities. In severe cases, individuals with Buerger's disease may exhibit tissue death (gangrene) of affected limbs.

\section{Etiology and epidemiology}

The specific cause of Buerger's disease is not known; however, in the majority of cases, patients are heavy tobacco users. Majority of patients with burger's diseases had a history 
of smoking, with early age smoking initiation [2]. Smoking men are frequently effected (20:3) than women [3], the former in term have much higher genetic tendency to intravascular necrosis. Lower extremities more commonly affected than upper. Those affected were from lower socio economic status with lowered education and poorly protected. The cigarettes smoking were in the range of 3-82 cigarettes/day with an average of 23 cigarettes/ day [4]. In the early hours to the initiation of smoking the duration of smoking was ranged from 3 months to about 34 years. Most of the established smokers (about 87\%) had concurrent opium addiction. Out of this double addiction, nearly one third had (26\%) $\%$ become addicted because of their body pain or the despair and distress after leg surgical intervention for gangrenous parts of legs.

\section{Progression and diagnosis}

Some patients may experience a variable period of remissions or relapses, depending upon the frequency of smoking. Evidence of gangrene is defined in cases of advanced inflammatory changes of main vessels and collaterals coupled with infection and tissue necrosis (SDA, 2003). Owing to the dose-dependent nature of Buerger's disease leading to frequent relapse in some cases, it can be confused with severe Raynaud's phenomenon, which is caused by periodic spasm, rather than occlusion, of veins and arteries. Biopsy, histopathology, and arteriography confirm the nature of disease [5].

\section{Treatment}

Smoking cessation, good nursing care, and appropriate antibiotic regimens can improve the outlook for patients with early peripheral vascular disease. Aggregate data show that 70\%$80 \%$ of patients with effective smoking cessation, nursing care, and prompt follow up improve without proceeding to amputation [6]. Hospitalization and prolonged treatment may be required in the $10 \%-15 \%$ patients with infection, impaired circulation, and evidence of tissue necrosis [7]. In these cases, arterial bypass of the effected vessels and debridement are indicated. A recent analysis showed that $5 \%-9 \%$ of gangrene patients proceeded to inevitable amputation [8]. These patients were characterized by poor collateral circulation, evidence of occlusion of the main vessels, complicated infection, and poor early prognosis. Treatment with glucocorticoids and anticoagulants has not been shown to have an active role in the prognosis or course of the disease [9].

\section{Discussion}

Thromboangiitis obliterans (Buerger's disease) is an important complication of smoking that mostly affects young and middle-aged males. Smoking has been found to be directly proportional to the course of Buerger's disease. A strong doseresponse relationship exists with the severity of disease, on one hand, and frequency and duration of smoking on the other (Figure 5). Early presentation for treatment, arteriography and appropriate antibiotic treatment and nursing care are associated with good prognosis. Poor collateral circulation, occlusion of the main vessels, and complicated infection are associated with necessity for amputation. These data have important implications for health care providers. Patients with history of smoking should be strongly advised to undergo cessation programs and treatments to improve overall health and prevent or treat peripheral vascular disease. Public health agencies should continue emphasis on tobacco control and health education policies, and educators should include tobacco avoidance with regular curricula at an early stage. Additionally, research and reviews like the present article are important, especially in developing countries. In such areas, there may be less data available regarding the health consequences of tobacco use, enabling the tobacco industry to continue to deny the hazards of tobacco use. Regular reporting on health consequences of tobacco use is important to change public opinion and improve public health.

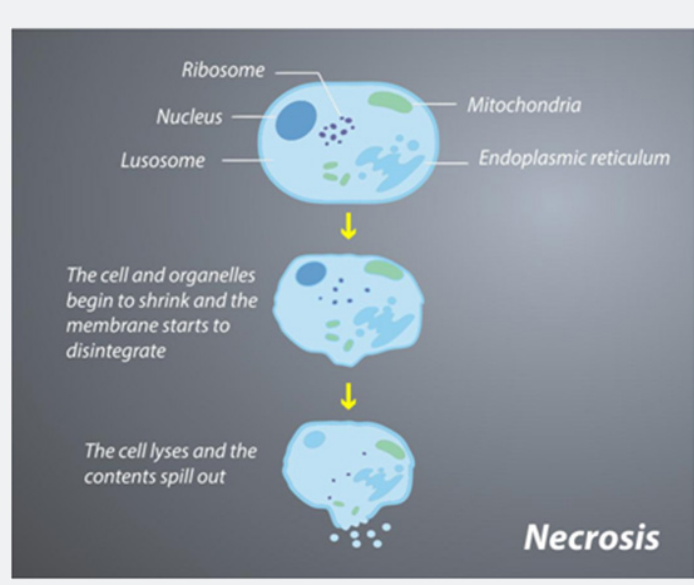

Figure 5

\section{References}

1. Pillai SR, Nair BC, Babu S (2016) Anaesthesia for peripheral vascular disease. Journal of Research in Anaesthesiology and Pain Medicine 2(1): 13-17.

2. Issa AA, Newman M, Simman R (2014) Toe necrosis, etiologies and management, a case series. J Am Coll Clin Wound Spec 5(2): 26-35.

3. Fazeli B (2010) Buerger's disease as an indicator of socioeconomic development in different societies, a cross-sectional descriptive study in the North-East of Iran. Arch Med Sci 6(3): 343-347.

4. Małecki R, Zdrojowy K, Adamiec R (2009) Throm-boangiitis obliterans in the $21^{\text {st }}$ century-A new face of disease. Atherosclerosis 206(2): 328334.

5. Hallet JW (2014) Peripheral arterial disease. Merck Sharp \& Dohme Corp, Kenilworth, New Jersey, USA.

6. Jones WS, Schmit KM, Vemulapalli S, Subherwal S, Patel MR, et al. (2013) Treatment strategies for patients with peripheral artery disease.

7. Gemechu FW, Seemant F, Curley CA (2013) Diabetic foot infections. Am Fam Physician 88(3): 177-184.

8. MacGill M (2016) Gangrene: causes, symptoms, and treatment. Medi Lexicon International, Bexhill-on-Sea, England, UK.

9. Boudi FB, Subhi Ali Y (2014) Noncoronary atherosclerosis overview of atherosclerosis. Medscape. 

(C) This work is licensed under Creative DOI: 10.19080/JOCCT.2018.11.555809
Your next submission with Juniper Publishers will reach you the below assets

- Quality Editorial service

- Swift Peer Review

- Reprints availability

- E-prints Service

- Manuscript Podcast for convenient understanding

- Global attainment for your research

- Manuscript accessibility in different formats

( Pdf, E-pub, Full Text, Audio)

- Unceasing customer service

Track the below URL for one-step submission https://juniperpublishers.com/online-submission.php 